\title{
Green sulfur-extended asphalt concrete: mix design of the complex binder
}

\author{
Vitaliy Gladkikh ${ }^{1,}$, Evgeniy Korolev ${ }^{1}$, Valentina Gladkikh $^{2}$ \\ ${ }^{1}$ Moscow State University of Civil Engineering, Nanomaterials and Nanotechnology Research and \\ Educational Centre, Yaroslavskoye hw. 26, 129337, Moscow, Russian Federation \\ ${ }^{2}$ Orenburg State University, Prospekt Pobedy13, 460018, Orenburg, Russian Federation
}

\begin{abstract}
Using the ordinary sulfur extended asphalt leads to emission of toxic gases. The efficient method to prevent the emission is to use other admixtures as suppressors, but this requires the complication of the mix design scheme. In the present work we have extended the well known design method for the case of complex binder with arbitrary number of suppressors. The example of application of the proposed method is given. The results indicate that even for the relatively small amounts of suppressors it is better to use the correct mix design scheme.
\end{abstract}

\section{Introduction and prior work}

The researchers from different universities and companies all around the world consider the production of durable, energy-efficient and environmentally friendly asphalt concrete pavements as a significant goal. Enhancement of functional reliability of asphalt concrete pavements is currently associated with application of various modifying admixtures that enhance the operational properties of pavements. Among the mentioned admixtures are thermoplastic elastomers, rubber grains and several others [1-4]. The technical sulfur is also currently accepted as and efficient admixture for asphalt concrete. Asphalt concretes that are prepared with complex binder made of bitumen and technical sulfur are known as sulfur-extended asphalts (SEA) concretes. Because of numerous alterations in chemical and phase composition of bitumen, and also due to relatively intensive interaction at the phase interface, such materials are characterized by improved operational properties (especially for increased temperatures of operation), including resistance to rutting, fatigue life, water resistance, etc. [5-12].

However, widespread practical use of ordinary SEA is not possible because of environmental impact. For such SEA the emission of toxic gases (hydrogen sulfide and sulfur dioxide) takes place both during the concrete mix preparation and pavement production stages. The ecological aspects of SEA concretes application were considered quite early [13] and attract even more attention in recent research works [14-22]. Because of this, numerous toxic gas neutralizers that make the application of SEA concretes possible are successfully developed. Unfortunately, in case of many additional emission suppressors,

* Corresponding author: gladkich_87@mail.ru 
well known methods that were proposed in, e.g., [23] and [24], can not be directly used to design the binder. Thus, the method of SEA mix design requires modification.

\section{Basic mix design scheme}

As before, the basis of mix design will be the obvious statement that volume of composition is the sum of components' volumes:

$$
\sum_{i=1}^{N} \frac{m_{i}}{\rho_{i}}=V
$$

where $m_{i}$ is the mass of $i$-th component, $\rho_{i}$ is the density of $i$-th component, $N$ is the number of components.

There are numerous local documents that regulate the rules of grain size distribution and volumetric ration of the binder in asphalt concrete; in Russian Federation there are RU GOST 31015-2002 and RU GOST 9128-2013. In case of SEA concretes such documents can still be used as guides during design of grain size distribution.

As it was stated in, e.g., [24], for SEA concretes it is necessary to alter the volumetric ratio between binder and disperse phases since rheological properties of bitumen and sulfur-bitumen mix are different (the viscosity of sulfur at preparation stage is significantly lower). However, below we are going generalize the mix design scheme for complex binder - SEA with fine powders of suppressors of toxic gases. In general case, we can assume almost nothing about the viscosity of complex binder. Because of this we state that optimal structure of concrete (minimal porosity) corresponds to constant volumetric ratio between the binder and disperse phases: regardless of the amount of sulfur that is added to the bitumen, the resulting volume of binder should be equal to the volume of bitumen in asphalt concrete without the addition of sulfur:

$$
\frac{B_{0}}{\rho_{b}}=\frac{S B B}{\rho_{s b b}},
$$

where $\mathrm{B}_{0}$ is the optimal mass of bitumen in concrete mix (as it can be found during the design according to the local regulations), $\rho_{b}$ is the density of bitumen, $S B B$ is the amount of sulfur-bitumen binder (ordinary SEA), $\rho_{s b b}$ is density of sulfur-bitumen binder.

Optimal amount of sulfur-bitumen binder in sulfur-extended concrete mix can be expressed as follows:

$$
S B B=B_{0} \frac{\rho_{s b b}}{\rho_{b}} .
$$

To find out the density of sulfur-bitumen binder we can use Eq. (1):

$$
\frac{B}{\rho_{b}}+\frac{S}{\rho_{s}}=1
$$

where $B$ and $S$ are masses of bitumen and sulfur per unit volume, respectively.

Also, for the unit volume the following equation holds:

$$
S+B=\rho_{s b b} .
$$

Thus, we have:

$$
\rho_{s b b}=\left[\frac{1}{\rho_{b}}-a\left(\frac{1}{\rho_{b}}-\frac{1}{\rho_{s}}\right)\right]^{-1},
$$

where $a$ is the ratio of sulfur in sulfur-bitumen binder $(a<1)$.

Substituting Eq. (6) in Eq. (3) we get: 


$$
S B B=B_{0}\left[1-a\left(1-\frac{\rho_{b}}{\rho_{s}}\right)\right]^{-1} .
$$

Specific mass of bitumen in sulfur-bitumen binder:

Specific mass of sulfur:

$$
B_{1}=(1-a) B_{0}\left[1-a\left(1-\frac{\rho_{b}}{\rho_{s}}\right)\right]^{-1} \text {. }
$$

$$
S_{1}=a B_{0}\left[1-a\left(1-\frac{\rho_{b}}{\rho_{s}}\right)\right]^{-1}
$$

The expressions (8) and (9) differ from the known design scheme [23, 24] only by form (and, obviously, different data are required to use the derived equations).

\section{Extended mix design scheme}

Now we will take into account the presence of $k$ additional disperse phases - emission suppressors. Again, we can use Eq. (1):

$$
\frac{B}{\rho_{b}}+\frac{S}{\rho_{s}}+\sum_{i=1}^{k} \frac{N_{i}}{\rho_{i}}=1,
$$

where $N_{i}$ is the mass of $i$-th suppressor per unit volume, $\rho_{i}$ is the density of $i$-th suppressor.

We can also express the mass of $i$-th suppressor as follows:

$$
N_{i}=c_{i} S,
$$

where $c_{i}$ is the ratio of $i$-th suppressor in complex binder.

The specific mass of bitumen in complex binder with $k$ different suppressors is equal to:

$$
B_{1}=\left[1-a\left(1+\sum c_{i}\right)\right] \rho_{s b b} .
$$

Taking into account both Eq. (11) and Eq. (12) we have:

$$
\left[1-a\left(1+\sum_{i=1}^{k} c_{i}\right)\right] \frac{\rho_{s b b}}{\rho_{b}}+\frac{a \rho_{s b b}}{\rho_{s}}+a \rho_{s b b} \sum_{i=1}^{k} \frac{c_{i}}{\rho_{i}}=1 .
$$

The last equation can be solved for $\rho_{s b b}$ :

$$
\rho_{s b b}=\left\{\left[1-a\left(1+\sum_{i=1}^{k} c_{i}\right)\right] \rho_{b}^{-1}+\frac{a}{\rho_{s}}+a \sum_{i=1}^{k} \frac{c_{i}}{\rho_{i}}\right\}^{-1} .
$$

Optimal amount of complex binder with suppressors of toxic gases is equal to:

$$
S B B=\frac{B_{0} \rho_{s b b}}{\rho_{b}},
$$

thus, for the specific mass of sulfur in complex binder with suppressors of toxic gases we get:

$$
S_{1}=\frac{a B_{0} \rho_{s b b}}{\rho_{b}} .
$$

Taking into account three last equations, we derive the following expression for the specific mass of sulfur:

$$
S_{1}=a B_{0}\left\{\left[1-a\left(1+\sum_{i=1}^{k} c_{i}\right)\right]+a \frac{\rho_{b}}{\rho_{s}}+a \sum_{i=1}^{k} c_{i} \frac{\rho_{b}}{\rho_{i}}\right\}^{-1} .
$$

Specific mass of $i$-th suppressor: 


$$
H_{i}=a B_{0} c_{i}\left\{\left[1-a\left(1+\sum_{j=1}^{k} c_{j}\right)\right]+a \frac{\rho_{b}}{\rho_{s}}+a \sum_{j=1}^{k} c_{j} \frac{\rho_{b}}{\rho_{j}}\right\}^{-1} .
$$

And, finally, the specific mass of bitumen in complex binder is:

$$
B_{1}=\left[1-a\left(1+\sum_{i=1}^{k} c_{i}\right)\right] B_{0}\left\{\left[1-a\left(1+\sum_{i=1}^{k} c_{i}\right)\right]+a \frac{\rho_{b}}{\rho_{s}}+a \sum_{i=1}^{k} c_{i} \frac{\rho_{b}}{\rho_{i}}\right\}^{-1} .
$$

It can easily be proven that for the mix without suppressors $(k=0)$ expressions $(17)$ and (19) becomes expressions (9) and (8), respectively.

\section{Examples of mix design}

\subsection{Example 1: basic design}

We need to design the ordinary SEA without any suppressors of toxic gases.

Reference data: density of sulfur is $2070 \mathrm{~kg} / \mathrm{m}^{3}$, density of bitumen is $1000 \mathrm{~kg} / \mathrm{m}^{3}$.

Given data: amount of sulfur in SEA is $30 \%$, specific mass of the bitumen for reference grain size distribution is $52.5 \mathrm{~kg}$ per ton.

The density of SEA can be determined by Eq. (6):

$$
\rho_{s b b}=\left[\frac{1}{\rho_{b}}-a\left(\frac{1}{\rho_{b}}-\frac{1}{\rho_{s}}\right)\right]^{-1}=\left[\frac{1}{1000}-0.3 \cdot\left(\frac{1}{1000}-\frac{1}{2070}\right)\right]^{-1}=1183.5 \mathrm{~kg} / \mathrm{m}^{3} .
$$

Specific mass of bitumen can be found by Eq. (8):

$B_{1}=(1-a) B_{0}\left[1-a\left(1-\frac{\rho_{b}}{\rho_{s}}\right)\right]^{-1}=[(1-0.3) \cdot 52.5] \cdot\left[1-0.3 \cdot\left(1-\frac{1000}{2070}\right)\right]^{-1}=43.5 \mathrm{~kg}$ per ton.

Specific mass of sulfur:

$$
S_{1}=a B_{0}\left[1-a\left(1-\frac{\rho_{b}}{\rho_{s}}\right)\right]^{-1}=0.3 \cdot 52.5 \cdot\left[1-0.3 \cdot\left(1-\frac{1000}{2070}\right)\right]^{-1}=18.64 \mathrm{~kg} \text { per ton. }
$$

The results are summarized in Table 1.

Table 1. Basic mix design of the SEA.

\begin{tabular}{|c|c|}
\hline Component & Specific mass, kg per ton \\
\hline Bitumen & 43.5 \\
\hline Sulfur & 18.24 \\
\hline Specific mass of the SEA & 62.14 \\
\hline
\end{tabular}

As we can see from Table 1, the specific mass of bitumen is decreased (part of the bitumen is replaced by sulfur), while specific mass of the SEA is increased (due to higher density of sulfur). Thus, taking into account prices of sulfur and bitumen, we can expect the SEA concrete of slightly lower price and slightly higher density.

\subsection{Example 2: extended design}

We need to design the complex binder with single suppressor of toxic gases.

Reference data: density of suppressor is $6310 \mathrm{~kg} / \mathrm{m}^{3}$, other reference data are the same. 
Given data: amount of sulfur in complex binder is $30 \%$, specific mass of the bitumen for reference grain size distribution is $52.5 \mathrm{~kg}$ per ton, number $k$ of suppressors is 1 , sulfur/suppressor mass ratio is $30 \%$.

Specific mass of bitumen (Eq. (19)):

$$
\begin{gathered}
B_{1}=\left[1-a\left(1+\sum_{i=1}^{1} c_{i}\right)\right] B_{0}\left\{\left[1-a\left(1+\sum_{i=1}^{1} c_{i}\right)\right]+a \frac{\rho_{b}}{\rho_{s}}+a \sum_{i=1}^{1} c_{i} \frac{\rho_{b}}{\rho_{i}}\right\}^{-1}= \\
=[1-0.3 \cdot(1+0.05)] \cdot 52.5 \cdot\left\{[1-0.3 \cdot(1+0.05)]+0.3 \cdot \frac{1000}{2070}+0.3 \cdot 0.05 \cdot \frac{1000}{6310}\right\}^{-1}=43.21 .
\end{gathered}
$$

Specific mass of sulfur (Eq. (17)):

$$
\begin{gathered}
S_{1}=a B_{0}\left\{\left[1-a\left(1+\sum_{i=1}^{1} c_{i}\right)\right]+a \frac{\rho_{b}}{\rho_{s}}+a \sum_{i=1}^{1} c_{i} \frac{\rho_{b}}{\rho_{i}}\right\}^{-1}= \\
=0.3 \cdot 52.5 \cdot\left\{[1-0.3 \cdot(1+0.05)]+0.3 \cdot \frac{1000}{2070}+0.3 \cdot 0.05 \cdot \frac{1000}{6310}\right\}^{-1}=18.92 .
\end{gathered}
$$

Specific mass of suppressor (Eq. (18)):

$$
\begin{gathered}
H_{1}=a B_{0} c_{1}\left\{\left[1-a\left(1+\sum_{j=1}^{1} c_{j}\right)\right]+a \frac{\rho_{b}}{\rho_{s}}+a \sum_{j=1}^{1} c_{j} \frac{\rho_{b}}{\rho_{j}}\right\}^{-1}=. \\
=0.3 \cdot 52.5 \cdot 0.05 \cdot\left([1-0.3 \cdot(1+0.05)]+0.3 \cdot \frac{1000}{2070}+0.3 \cdot 0.05 \cdot \frac{1000}{6310}\right)^{-1}=0.95 .
\end{gathered}
$$

The results are summarized in Table 2.

Table 2. Extended mix design of the complex binder.

\begin{tabular}{|c|c|}
\hline Component & Specific mass, kg per ton \\
\hline Bitumen & 43.21 \\
\hline Sulfur & 18.92 \\
\hline Suppressor & 0.95 \\
\hline Specific mass of the complex binder & 62.64 \\
\hline
\end{tabular}

As it can be decided from Table 2, even for the relatively small amounts of suppressors, it is better to use the correct mix design scheme: the difference in densities between sulfur and suppressor leads to noticeable alteration of the specific masses of components.

\section{Summary and conclusion}

Despite the fact that the use of sulfur as an extender in asphalt paving mixtures could perform in a satisfactory manner [11], using the ordinary SEA leads to serous problem. The main hazard is the emission of hydrogen sulfide and sulfur dioxide during mixing and dumping operations. The efficient method to prevent the emission of toxic gases is to use numerous suppressors; obviously, this requires the complication of the mix design scheme.

In the present work we have extended the SEA design method for the case of complex binder with arbitrary number of extra phases. The offered method allows precise calculation of specific masses of all components. The example of application of the proposed method is given. The results indicate that even for the relatively small amounts of suppressors, it is 
better to use the correct mix design scheme: the difference in densities between sulfur and suppressor leads to noticeable alteration of the specific masses of components.

This work is supported by grant of Russian Federation President GP-2627.2016.1.

\section{References}

1. V.G. Nikolsky, I.A. Krasotkina, Automotive roads 2, 37-40, (2010)

2. A.B. Solomentsev, Science and Technology for Road Construction 1, 14-16, (2008)

3. L.M. Gochman, Pavements based on Sulfur-Extended Asphalts with Polymers, Moscow: Infoavtodor (2002)

4. M.A. Vysotskaya, D.A. Kusnetsov, Building Materials 12, 63-64 (2013)

5. Yu.E. Vasilyev, O.A. Voyeyko, D.S. Tsarkov, Naukovedeniye 5, (2014)

6. V.A. Gladkikh, E.V. Korolev, D.L. Khusid, Building Materials, Equipment and Technologies of XXI Century, 194, 30-33, (2015)

7. E.V. Korolev, V.A. Gladkikh, V.A. Smirnov, Advanced Materials and Structural Engineering: Proc. of the Intl. Conf. on Advanced Materials and Engineering Structural Technology, 285-288 (2015)

8. V.Z. Gnateyko, The use of sulfur and sulfur-containing waste in road construction, Highways: an overview, Moscow: Minavtodor (1990)

9. T.W. Kennedy, R. Haas, P. Smith, G.A. Kennepohl, E.T. Hignell, Transportation Research Record 659, 12-17 (1977)

10. M. Mazumdar, S.K. Rao, Transportation Research Record 1417, 144-149 (1993)

11. T.L. Beatty, K. Dunn, E.T. Harrigan, K. Stuart, H. Weber, Transportation Research Record 1115, 161-170 (1987)

12. R. Hou, Z.-Y. Guo, Journal of Building Materials 16, 525-528 (2013)

13. D.Y. Lee, Industrial and Engineering Chemistry Product Research and Development, 14, 171-177 (1975)

14. P. Qian, H. Qiao, Q. Ma, Journal of Southeast University (Natural Science Edition), 39, 592-597 (2009)

15. J. Colange, D. Strickland, G. McCabe, K. Gilbert, R. May, S. Banbury, Road Materials and Pavement Design 11, 459-485 (2010)

16. H.A. Kadkhodaei, H. Shabani, M. Shapouri, G. Karimi, Proc. of the 8th International Chemical Engineering Congress \& Exhibition (IChEC 2014), (2014)

17. Gladkikh, V.A. \& Korolev, E.V, Advanced Materials Research 1040, 387-392 (2014)

18. V.A. Gladkikh, E.V. Korolev, D.L. Khusid, Building materials, equipment and technologies of XXI century 194, 30-33 (2015)

19. O.I. Doshlov, I.A. Kalapov, Journal of the Irkutsk State Technical University 11, 107$111(2015)$

20. G.H. Shafabakhsh, M. Faramarzi, M. Sadeghnejad, Construction and Building Materials 98, 456-464 (2015)

21. E.R. Souaya, S.A. Elkholy, A.M.M. Abd El-Rahman, M. El-Shafie, I.M. Ibrahim, Z.L. Abo-Shanab, Egyptian Journal of Petroleum 24, 483-491 (2015)

22. E.V. Korolev, V.A. Gladkikh, V.A. Smirnov, Advanced Materials and Structural Engineering: Proc. of the Intl. Conf. on Advanced Materials and Engineering Structural Technology, 285-288 (2015)

23. W.C. McBee, T.A. Sullivan, and J.O. Izatt, State-of-the-Art Guideline Manual for Design, Quality Control, and Construction of Sulfur-Extended Asphalt (SEA) Pavements, FHWA-IP-80-14, Implementation Package, US Department of Interior Bureau of Mines with The Sulphur Institute (1980)

24. W.C. McBee, T.A. Sullivan, D. Saylak, ASTM STP 724, 39-63 (1980) 